\title{
MANIPULACIÓN GENÉTICA Y TUTELA PENAL DE LA VIDA
}

\author{
Osvaldo Nelo Tieghi \\ Presidente de la Asociación de Criminología, Argentina
}

\section{Protección embrionaria.}

\section{a) Concepto.}

Entre la "vida de la especie» (filogénesis) y la «vida del hombre», o de la persona física, o de existencia visible (ontogénesis), hállase como posibilidad y condición de una y otra el "embrión»; el destino evolutivo ineluctable de éste ("embriogénesis») o "físíogénesis" es precisamente el hombre, con su presencia histórico-natural, políticosocial y religiosa en el pasado, presente y futuro, de la humanidad.

La «ontogénesis» se inscribe en la «filogénesis», en cuyo curso únicamente se hace posible. La "embriogénesis" se inscribe a su vez, en la "ontogénesis" que es la condición misma del "ovillo vital embrio-onto-filogenético". Imposible trazar una raya separativa entre la dinamogénesís filogenétíca, físio o embriogenética y ontogenética. No existe, sino un único proceso vital "filo-fisio-ontogenético" cuya protección se hace a través de la tutela a la vida del hombre y de la especie, desde sus instancias embrionarias (cfr., Tieghi y Gardella, Aborto..., 5 I).

El «embrión", o producto en desarrollo del "óvulo ya fecundado», o célula resultante de la fusión de dos "gametos", o "cigoto" debido a la "fecundación del óvulo", consecuencia de la "concepción» por unión del "espermio» y el "óvulo» ha sido y es considerado el "eslabón hereditario" propiamente humano que contiene todas las propiedades de su especie.

Desde 1978, cuando Robert Edwards y Patrick Steptoe logran el nacimiento de Louise Brown mediante "fecundación in vitro", en Cambridge, Gran Bretaña, a la protección del embrión natural se sumó la necesidad de tutelar los embriones producidos in vitro.

Corresponde señalar que antes de la unión (natural o in vitro) de los dos "gametos" (el "espermio" - masculino - y el "óvulo» - femenino -), esto es de su "fusión» no ha tenido lugar la formación o aparición del «nuevo patrimonio genético humano" destinado o dirigido natural y fisiogenéticamente al "nacimiento", a partir del momento mismo de la «concepción» - con el aporte por cada "gameto» de su «número aploide" o $n$ de "cromosomas"- nace, con la "reconstitución" del número $2 n$ normal de "cromosomas" (46), una célula humana individual e irrepetible que contiene a partir de allí toda la "información genética específica" y que se halla dotada de la capacidad de automultiplicación (Solomon, Villee, Davis, Biología, pgs. 236 y 237). 
Todo el "proceso embriogenético" desembocará ineluctablemente en el nacimiento de la «persona». ¡He allí la razón de su protección in útero (aborto) o fuera de él (v. gr., in vitro), como delito de daño o de peligro "contra la vida" (cfr., Tieghi, Osvaldo N. y Gardella, Norberto J. L., Aborto y anticoncepcionismo, 14 y ss.)!; parece innecesario explicitarla más allá. Inexplicable nos resulta, a su vez, la multiplicidad de teorías diversas acerca de la necesidad de uno o otro grado diferente de desarrollo embrionario o fetal; ello, dada su fatal e inherente naturaleza evolutiva, ab initio.

Se ha sostenido (cfr., v. gr., Lacadena, J. R., Genética..., 21 y ss.) que esta "singularidad genética" o "propiedad de unicidad" parece hallarse bajo duda en los supuestos de "gemelos monocigóticos y de «hermanos siameses». Sin embargo, tal unicidad siempre se corresponde - desde el nivel de observación biológico - con determinadas regularidades bajo observación. De allí, entonces, que aquellas hipótesis no afectan la esencia de la mencionada regla.

Se ha dicho, asimismo, que los supuestos referidos en el párrafo anterior pondrían en "crisis» a las "revelaciones de orden teológico» sobre el "alma»; pero el método propio al "conocimiento científico" - por su necesaria "facticidad", "perfectibilidad", "falibilidad», "verificabilidad», "control experimental», "relatividad», "utilidad», etc.-, jamás podría aprehender a tales "revelaciones» como hipótesis experimentales. Tanto menos podría tal método alcanzar un mismo «marco de referencia cognitivo" susceptible de validar pretendidas confirmaciones, rechazos o contradicciones significativas algunas con o de las mismas.

De lo expuesto resulta indubitable - por lo demás - que existen límites y niveles éticos religiosos y de "defensa social natural» cuya axiología condiciona necesariamente toda "conducta de manipulación tecnológica o instrumental" del orden que fuere.. Se suele afirmar, por ej. (Lacadena, cit., 21 y 22) que la Iglesia nos enseña que la existencia del alma humana es un acto creador de Dios que se repite para cada ser humano. Así, se dice, si ese acto creador ocurre - como así debería ser - en cuanto se constituye la nueva existencia humana, ¿qué sucede en el caso de los gemelos monocigóticos o idénticos cuya separación puede ocurrir durante las primeras divisiones de segmentación del cigoto anteriores a la formación de la cresta neural?; ¿el alma única, inicial, se escinde en dos? Y en el caso de los hermanos siameses, ¿aceptaríamos que tienen dos almas, cuando su unidad somática es muy grande? ¿Qué determinaría la presencia de una o dos almas? ¿a partir de qué situación biológicoanatómica diríamos que hay una o dos personas?

Quien se efectúa desde un nivel biológico estas preguntas (v. gr., Lacadena, ob. cit., 21 y ss.) no puede ignorar, sin embargo, que ninguno de tales interrogantes pueden ser propuestos en términos de «hipótesis científicas", ni sometidas éstas - en su caso - a "observación», ni a "medición», ni a "control de variables», ni a manipulación alguna de estas últimas. De allí que - engañosamente - es solo posible sorprender a un lector desprevenido: Se trata de supuestas contradicciones señaladas a partir de interrogantes indebidamente planteados.

Sí cabe en cambio a la «razón natural» - sin desalojar de su lugar a los aportes empíricos alcanzados provisionalmente en cada época - así como también a la «defensa social de la especie», a la ética y a la moral de los pueblos, poner límites a cualquier tipo de "manipulación" sobre "su» vida en desarrollo: sea su "destrucción" destinada a "frustrar" su propio "curso evolutivo ontogenético» en cualquier "instancia 
embriogenétíca», sea su "reproducción artificial» ("clonación», "partenogénesis», "ectogénesis», etc.) o cualquier otro tipo de «manoseo genético humano».

Debe tenerse presente que la ciencia no puede responder ni filosofar mas allá de lo que resulta del propio material experimental cuyas variables se manipulan y controlan. Mas si dicho "material», objeto de tal "manipulación», es la propia vida del hombre y de la especie, ésta se halla plenamente legitimada a tal tutela; así lo hace, por lo demás, con todos los demás bienes cuyo ataque resulta penalmente significativo, tales como el honor, la honestidad, la libertad, etc.

\section{b) Protección de la vida intrauterina}

Así como toda acción o conducta dirigida a la muerte del ser humano nacido con vida ha sido y es considerada como "homicidio" (doloso, culposo) en toda la legislación universal, así también toda destrucción (intencional o culposa) de la vida anterior al parto (embrionario o fetal) o in útero o claustro materno recibe y debe recibir recepción penal a través de suficiente incriminación (cfr., v. gr., D., 1, 5, 7; D., 1, 5, 26; D., 37, 9 , $1 ; D ., 48,8,8$ - con pena de destierro en la mujer -; D., 48, 19, 38, 5 - condena al último suplicio o a las minas - según el suministro de abortivos delito de peligro hubiese provocado, o no, la muerte de la madre); D., 48, 19, 39 (con pena capital); F.J, $6,3,1$ y 6, 3, 7 (como delito de peligro dar yerbas para abortar); Part., 7, 8, 8 (pena de muerte a la mujer que perdiere - por yerbas - a la criatura en útero); Cód. Penal español de 1995 -BOE del 23/11/96-, arts. 144 a 146, incluyendo las lesiones al feto (arts. 157 y 158) y los delitos relativos a la manipulación genética (arts. 159 a 162); Cód. Penal de Chile, arts. 342 a 345; Cód. Penal de Brasil, arts. 124 a 128; Cód. Penal de Paraguay, arts. 351 a 354 (incluyendo, como delito de peligro, la venta de abortivos); Cód. Penal argentino, arts. 85 a 88; Cód. Penal uruguayo, arts. 325 a 328)

\section{Manipulación extrauterina del embrión. Genes e ingeniería genética.}

Pero tanto la "falibilidad", limitación que le es inherente a todo conocimiento por experimentación científica, como la "perfectibilidad", que obsta a que aquél pueda dar por absolutamente ciertas las "verificaciones» mas allá de su «relatividad instrumental», de las "variables controladas" y de la "analítica cognitiva» (cfr., p. ej., Bunge, La ciencia.... 19 y ss.) o "estudio fenoménico por descomposición de sus elementos", señalan límites a la ciencia para dar respuestas totalizadoras, como v. gr., cuál es el sentido y fin de la vida o cómo es el universo en su conjunto y su destino o el por qué del conocimiento. Todo ello no ha impedido en modo alguno, sin embargo, que la experimentación comenzara a "manipular» las propias bases de nuestra existencia; ello, con toda clase de programas que incluyeron desde la "formación artificial de vida embrionario fuera del útero materno" (v.gr., fecundación in vitro), hasta múltiples supuestos de "experimentación genética humana en laboratorio" con fin diferente a la procreación ( $p$. ej., ectogénesis, clonado, fecundación interespecífica, etc.). Más aún dentro de las posibilidades de la ingeniería genética, se ha procurado no sólo la "alteración del patrimonio genético de la especie», sino la producción - con 
eventual liberación - de toda clase de "armas biológicas o exterminadoras de la especie humana” (cfr., sobre la tutela contra éstas, Cód. Penal español, 1995, art. 160).

Una de los más terroríficos planes de la ingeniería genética es la de su utilización para producir - como indica el tipo punitivo del artículo 160 del Código Penal español vigente (1995) armas biológicas o exterminadoras de la especie humana.

Según nos informan entre otros Suzuki y Knudtson - en Genética, 196 y ss.- el uso de las tecnologías de ADN, bajo el pretexto de defensa expone como estrategias posibles a las siguientes: 1. Microbios modificados genéticamente (se crean nuevas generaciones de supergérmenes para aniquilar objetivos militarmente seleccionados); 2 . Armas étnicas (llevando a la producción o modificación de patógenos capaces de infectar miembros de un grupo racial o étnico particular y no indiferenciadamente); 3. Clonación de toxinas biológicas (se utilizan las técnicas de clonación de genes para producir masivamente venenos dentro de bacterias o levaduras, cultivadas en fermentadores, exactamente de la misma manera que ya hoy los biotecnólogos clonan proteínas humanas como la insulina). Este procedimiento les permitiría a los científicos militares fabricar enormes cantidades de venenos mortales como, v. gr., las de las serpientes, difíciles de lograr a partir de organismos naturales; 4. Armas agrícolas (permiten atacar masiva y exitosamente cosechas o ganados del enemigo y, eventualmente, de un enemigo económico, con dificultades para la detección de la intencional). El Código Penal de Chile da protección específica a esta conducta en su artículo 291.

El ilimitado daño a la vida del que puede ser capaz, como hipótesis, la ciencia y tecnología genéticas - que, como vimos, no se agotan en la "manipulación» relativa a la "fecundación in vitro" y en el congelamiento y destrucción masivos de los embriones "huérfanos y subnumerarios»- debe alertar a la sociedad, al legislador y al jurista respecto a los alcances que debe tener la regulación jurídica relativa a cualquier tipo de experimentación embrionario o genética humanas; ello, fundamentalmente en orden a los delitos de peligro contra la especie y más allá de la obvia protección al bien jurídico de la vida.

De cualquier modo y prescindiendo de lo expuesto, toda forma artificial de procreación es al menos, por sí, moralmente ilícita.

La ciencia encuentra su frontera cuando más allá de servir al hombre puede poner en sus manos, o por vía de los propios medios de experimentación y de control de variables, medios o resultados que constituyen su negación y la de su propia especie, hasta alcanzar el peligro de su aniquilamiento como eventualidad no descartable.

Antes de tratar las diversas hipótesis que deben ser incluidas en el Código Penal sustantivo, corresponde agregar que esta posición - señalada en el párrafo anterior - es seguida por innumerables juristas con razones más o menos similares a las que aquí hemos subrayado: v. gr., Omar U. Barbero (Aspectos éticos..., 914 y ss.); Chiapero de Bas y Victoria M. Tagle de Marrama (La protección..., 878 y ss.); María del Carmen Yarke (Relaciones jurídicas..., 881 y ss.); Roberto L. Adorno (Fecundación..., 947 y ss.); Domingo M. Basso (Nacer..., 260 y ss.; 305 y ss.), etc., y se compadece con las exigencias mínimas de una moral conforme con las leyes naturales y a la moral cristiana. 


\section{BIBLIOGRAFIA}

Andorno, Roberto I., Fecundación "in vitro " y valor de la vida humana, en El Derecho, t. 120 , p. 947.

Barbero, Omar U., Aspectos éticos de la biotecnología y manipulación de la vida humana, en La Ley, t. 1988-D, p. 914 y ss.

Basso, Domingo M., Nacer y morir con dignidad - bioética -, Corporación de abogados católicos, Bs. As., 1993.

Bunge, Mario, La ciencia, su método y su filosofía, Siglo veinte, 1969.

Carrara, Francisco, Programa de derecho criminal, Temis, Bogotá, 1967

Chiapero de Bas, Silvana M. y Tagle de Marrama, Victoria M., La protección jurídica del embrión, en Jurisprudencia Argentina, t. 1989-IV, ps. 878 y ss. 1975.

Cuello Calón, Eugenio, Derecho penal, parte especial, Bosch, Barcelona, 14ª ed.,

Dawkins, Richard, El gen egoísta, las bases biológicas de nuestra conducta, Salvat, Barcelona, 1993. 1980.

Fontán Balestra, Carlos, Tratado de derecho penal, Abeledo Perrot, Bs. As.,

Gesell, A. y Amatruda, C., Embriología de la conducta, Paidós, Bs. As., 1972.

Gómez, Eusebio, Leyes penales anotadas, Ediar, Bs. As., 1952. 1983.

Lacadena, Juan Ramón, Genética y condición humana, Alhambra, Madrid,

Mazeaud, Henri y León y Mazeaud, Jean, Lecciones de derecho civil, Ejea, Bs. As., 1974 .

Milunsky, Aubrey, Conozca sus genes, Troquel, Bs. As., 1982. 1965.

Penrose, L.S., Introducción a la genética humana, Eudeba, Bs. As., 2 ' ed.,

Ramos, Juan P., Derecho Penal, Arici, Bs. As., 1928.

Soler, Sebastián, Derecho penal argentino, TEA, Bs. As., 1963.

Solomon, E.P., Villee, C.A. y Davis, P.W., Biología, Intematnericana, México, 1987.

Suzuki, David y Knudtson, Peter, Genética, Tecnos, Madrid, 1991.

Tejedor, Carlos, Proyecto de Código Penal para la República Argentina, Imprenta del Comercio del Plata, Bs. As., 1866.

Tieghi, Osvaldo N. y Gardella, Norberto J.L., Aborto y anticoncepcionismo, Unión de padres de familia de Río Gallegos, Santa Cruz, 1980.

Varela, Bernardo C., Homicidio simple, Lerner, Córdoba, 1969. 
Revista de Derecho - Universidad Católica del Norte - Sede Coquimbo - 1997

Winchester, A.M., Introducción a la genética humana, Alhambra, Madrid, 1980.

Yarke, María del Carmen, Relaciones jurídicas que determina la manipulación genética, en Jurisprudencia Argentina, t. 1989-11, ps. 881 y ss. 